\title{
DIMENSÕES BIOGRÁFICAS, RESPOSTAS COMUNITÁRIAS: TENSÕES NUMA POLITIICA SOCIOEDUCACIONAL EM PORTUGAL
}

\author{
Fátima Antunes' \\ Rosanna Barros"
}

\section{Resumo}

Neste artigo ${ }^{1}$ debatemos sentidos da microintervenção educacional levada a cabo em projetos de âmbito comunitário. Interessou-nos estudar implicações entre as novas lógicas de gestão pública e a gestão de desigualdades sociais e escolares, que o Programa InovAção (PI) traduz. A análise dos dados sugere a ambivalência de sentidos e resultados da microintervenção comunitária: observam-se práticas, apoiadas em compromissos sociais alargados, de construção coletiva da capacitação individual (a gestão do eu, aprender o ofício de aluno, normalizar biografias académicas) em tensão com a vinculação a respostas educacionais de cariz remediativo e orientações para a individualização e localização das intervenções face a problemas escolares, de que são objeto os sujeitos excluídos.

\section{GOVERNAÇÃO • FRACASSO ESCOLAR • ABANDONO ESCOLAR • DESIGUALDADES SOCIOEDUCATIVAS}

\section{BIOGRAPHICAL DIMENSIONS, COMMUNITY RESPONSES: TENSIONS OF A SOCIOEDUCATIONAL POLICY IN PORTUGAL}

\section{Abstract}

In this article we discuss the meanings of educational micro-intervention carried out in community-based projects. We aimed to study the implications of the new rationales of public management and the management of social and school inequalities, present in the Programa InovAção [Innovation Program] (PI). The analysis of the data suggests the ambivalence of meanings and results of community micro-intervention: we observed practices, supported by broad social commitments, of collective construction of individual empowerment (the management of the self, learning the task of the pupil, normalising academic biographies); these practices were inhabited by tensions coming from the connection to remedial educational responses and guidelines towards the individualization and localisation of interventions facing school problems, which have by object the subjects excluded.

\section{GOVERNANCE - SCHOOL FAILURE - SCHOOL DROP-OUT • SOCIOEDUCATIONAL INEQUALITIES}

I Centro de Investigação em Educação (ClEd), Universidade do Minho, Braga, Portugal; http://orcid.org/0000-0001-9045-7757; fantunes@ie.uminho.pt

II Centro de Investigação sobre o Espaço e Organizações (CIEO), Universidade do Algarve, Faro, Portugal; http://orcid.org/0000-0002-3882-1539; rosanna@net.sapo.pt

1 A pesquisa foi desenvolvida no âmbito do Centro de Investigação da Educação (CIEd) do Instituto de Educação da Universidade do Minho, financiada pela Fundação para a Ciência e Tecnologia (FCT) (PTDC/MHC/CED/3775/2014). Este artigo analisa dados parcelares de um projeto mais vasto, Políticas, Governação e Administração da Educação, em que participam 19 investigadores portugueses: A. Afonso, A. P. Macedo, C. A. Gomes, C. Estevão (até 2014), C. Rocha, D. Silva, E. Veloso, E. Vilarinho, F. Martins, G. Silva, J. Palhares, M. A. Silva, M. J. Carvalho, M. J. Casa-Nova, L. Torres, L. Lima, V. Sá e as autoras. Os textos da introdução e do referencial teórico inscrevem-se parcialmente nesse projeto mais amplo. 


\section{DIMENSIONS BIOGRAPHIQUES, RÉPONSES COMMUNAUTAIRES: TENSIONS CONCERNANT UNE POLITIQUE SOCIO-ÉDUCATIVE AU PORTUGAL}

\section{Résumé}

Dans cet article, nous discutons le sens d'une micro-intervention éducative mise en place dans le cadre de projets communautaires. Nous avons cherché à étudier les implications entre les nouvelles logiques de gestion publique et la gestion des inégalités sociales et scolaires, que le Programa InovAção [Programme Innovation] (PI) traduit. L'analyse des données suggère l'ambivalence du sens et des résultats de cette micro-intervention communautaire: on observe des pratiques qui sont soutenues par de grands engagements sociaux et visent la construction collective de la capacitation individuelle (gestion de soi, apprentisage du métier d'élève, normalisation des biographies académiques), mais qui entrent en tension avec les réponses éducatives mises en oeuvre pour les sujets exclus, telles que le rattrapage scolaire, et les orientations pour l'individualisation et la localisation des interventions face aux problèmes scolaires.

\section{GOUVERNANCE • ÉCHEC SCOLAIRE • DÉCROCHAGE・INÉGALITÉS SCOLAIRES}

\section{DIMENSIONES BIOGRÁFICAS, RESPUESTAS COMUNITÁRIAS: TENSIONES EN UNA POLÍTICA SOCIOEDUCATIVA EN PORTUGAL}

\section{Resumen}

En este artículo discutimos los sentidos de la microintervención educativa llevada a cabo en proyectos comunitarios. Nos interesó estudiar las implicaciones entre las nuevas lógicas de la gestión pública y la gestión de las desigualdades sociales y escolares, que refleja el Programa InovAção [Programa Innovación] (PI). El análisis de los datos muestra la ambivalencia de los sentidos y resultados de la microintervención comunitaria: se observan las prácticas, respaldadas por amplios compromisos sociales, de construcción colectiva de la capacitación individual (autogestión, aprender el oficio de alumno, normalizar biografías académicas) en tensión con la vinculación a respuestas educativas correctivas y pautas para la individualización y localización de intervenciones frente a problemas escolares, de las que son objeto los sujetos excluidos.

\section{GOBERNANCIA • FRACASO ESCOLAR • ABANDONO ESCOLAR • DESIGUALDADES SOCIOEDUCATIVAS}


SUPERAÇÃO DO INSUCESSO E ABANDONO ESCOLARES CONSTITUIU-SE UM DOS FOCOS centrais de políticas europeias, desde há cerca de duas décadas, fundadas em finalidades e opções político-económicas em torno da competitividade e coesão social (COUNCIL OF THE EUROPEAN UNION, 2002). Portugal é um dos países em que aquelas realidades e desigualdades socioeducativas verificam um nível elevado, ao mesmo tempo que se observam esforços e resultados significativos no sentido da concretização do direito à educação (EUROSTAT, 2016, p. 187). Uma das expressões dessas especificidades das realidades educativas portuguesas é a assimetria e intensidade do insucesso e abandono escolares em certas comunidades, não raro com marcas de segregação étnica, em condições de desvantagem socioeconómica particularmente aguda (EUROPEAN UNION AGENCY FOR FUNDAMENTAL RIGHTS, 2014, p. 12, 15, 18-21). Nesse contexto, desde há vários anos são desenvolvidos projetos de microintervenção comunitária expressamente orientados para a inclusão escolar de públicos em condições de défice e privação do direito à educação, enquanto condição de acesso e exercício da cidadania.

A democracia é, tal como propõe Bobbio (1988), a forma de governo que articula melhor a dimensão ética com a dimensão política, a dimensão do reconhecimento e legitimidade da existência dos outros com a dimensão de uma vida em comum, a dimensão do controlo popular com a da igualdade política. Porém, nos tempos atuais, a emergência de um estado pós-social minimalista tem vindo a reconfigurar 
cada vez mais as práticas de democracia, com novas desigualdades a aparecer perante um claro declínio da esfera pública e da própria noção de justiça social.

Com efeito, na atual fase do Estado neoliberal e da pós-democracia (CROUCH, 2004), a justiça tende a tornar-se uma mera exsudação do próprio mercado, ao mesmo tempo que a imposição da justiça social por parte do Estado é incompatível com a divergência moral da sociedade moderna. Na verdade, verifica-se hoje uma certa impulsão para a desformalização da ideia de justiça social, ou para a sua perceção como oferta apenas de garantias contingentes, ou ainda, para a sua limitação ao cumprimento de direitos sociais de baixa intensidade, de assistência aos mais desfavorecidos, de neopietismo, em que as intervenções devem obedecer a uma espécie de nova subsidariedade do social: “o público é para os que não podem alcançar o privado” (ALONSO, 2000, p. 179).

No campo da educação, os ecos dessas transformações fazem-se também ouvir. Como sublinham Meo e Milstein (2018), diversos estudos têm analisado quer "a instauração de mecanismos de quase-mercado e [...] a emergência do mundo dos negócios e da sociedade civil na organização e definição de aspetos centrais do que se ensina, como e para quê", quer os "distintos ritmos e caraterísticas dos processos de descentralização" e os diversos efeitos do seu desenvolvimento (p. 4). Na verdade, os sistemas educativos, que eram tradicionalmente locais protegidos por discursos de bem comum, de serviço público, estão hoje a posicionar-se de modo a que a educação se apresente como um dos sectores de serviço cruciais para a economia e que a aprendizagem seja um dos melhores instrumentos da "governamentalidade flexível" (OLSSEN, 2004; TRIPODI; SOUSA, 2018). Consequentemente, a educação e a aprendizagem em todas as suas formas (formal, não formal e informal) já não devem ser sensíveis às origens sociais, políticas e culturais; o que importa são políticas sociais e educativas que veiculem valores que se encaixem na ética da análise custo-benefício.

Assim sendo, a justiça educacional e as medidas educativas que supostamente a acolhem emergem contaminadas pela normatividade gerencialista e mercantilista, dificultando a compreensão da educação em geral e das organizações educativas em particular como fóruns públicos, promotores de convivência democrática, abertos à participação, à contestação e ao debate, ao compromisso com a justiça social global (FERNANDES; ARAÚJO; GARCÍA DEL DUJO, 2018), o que significa uma preocupação clara com o bem comum e com a procura de igualdade de oportunidades educativas e de vida. Nesse sentido, o estudo de políticas e programas socioeducativos, procurando observar e desvelar "o que fazem os atores”, permite problematizar e discutir os sentidos dessas políticas, "para lá dos propósitos enunciados pelas mesmas” (MEO; MILSTEIN, 2018, p. 14).

Ora, o Programa InovAção ${ }^{2}$ é uma política socioeducacional que em Portugal conta já com seis edições. Reconhecidamente,

2 Essa é uma designação fictícia. Ao longo do texto, quer o Programa InovAção (PI), quer os responsáveis políticos e técnicos dele, nacionais ou locais, bem como os Projetos ou os sujeitos são referidos com nomes e designações fictícias, conforme opção tomada no âmbito da investigação, no sentido de resguardar pessoas, instituições e contextos. O PI será aqui brevemente caraterizado. 


\begin{abstract}
Poucos programas em Portugal têm tido a duração do Programa InovAção que, iniciado em 2001, [...] detém mais de 10 anos de duração, o que lhe confere um caráter particular mas, sobretudo, Ihe permitiu uma capacidade reflexiva que facilitou um sucessivo ajustamento às conjunturas históricas da última década afinando objetivos e públicos-alvo ao longo do tempo. (AAVV, 2013, p. 30)
\end{abstract}

Trata-se de um Programa de âmbito nacional com especial potencial para a reconstituição de espaços de ação educacional, podendo relocalizar problemas escolares e inovar lógicas de intervenção comunitária, enquanto opera através de uma nova lógica de arranjos institucionais destinados a garantir o cumprimento da sua função, entendida como sendo a de "promover a inclusão social de crianças e jovens provenientes de contextos socioeconómicos mais vulneráveis, particularmente dos descendentes de imigrantes e minorias étnicas" (PORTUGAL, 2012, p. 4279).

Desse modo, o estudo que sustenta os dados que aqui se apresentam tem a ambição de analisar implicações entre essas mudanças socioeducacionais e a criação e gestão de desigualdades sociais e escolares. Interessou-nos explorar algumas dimensões do objeto de estudo, designadamente: (i) as perspetivas e cursos de ação dos atores envolvidos, com destaque quer para os técnicos, quer para as crianças, jovens e suas famílias (que no PI são provenientes de contextos socioeconómicos mais vulneráveis); e (ii) a questão da inserção escolar como problema de inclusão social. Com essas dimensões em observação, e encarando a realidade como uma realidade complexa, discutem-se as centralidades e periferias provocadas pela atual inovação nas lógicas de intervenção comunitária e o seu papel em relocalizar problemas escolares e em gerir dinâmicas de inclusão e exclusão social.

\title{
METODOLOGIA DA INVESTIGAÇÃO
}

A investigação educacional (plurianual e ainda em curso), que enquadra os dados aqui apresentados e discutidos, é de tipo qualitativo (GUBA; LINCOLN, 1994) e emprega o método sociológico da pesquisa de terreno (SMYTH; SHACKLOCK, 1998), privilegiando o uso do inquérito por entrevista semiestruturada (FONTANA; FREY, 1994). Nesta investigação educacional, como um todo, escolhemos deliberadamente entrevistar diferentes tipos de participantes envolvidos em distintas escalas de governação e implementação do PI. Ao nível macroanalítico, foram entrevistados quer o coordenador nacional, quer os coordenadores regionais do PI no norte e no sul do país. E ao nível microanalítico, serão ainda entrevistados os protagonistas dessa política socioeducacional portuguesa, ou seja, crianças e jovens que são os beneficiários diretos e que vivenciam no seu quotidiano várias dinâmicas de exclusão relacionadas com trajetórias escolares de insucesso, com baixas qualificações dos agregados familiares e muito baixo rendimento, com situações de desemprego na família ou trabalho precário e sazonal, com pertença 
a minorias étnicas ou realidades ambivalentes de migrantes, particularmente os descendentes das ex-colónias de África.

Ora, os dados aqui apresentados e discutidos referem-se apenas ao nível mesoanalítico, em que a focalização da investigação recaiu na gestão operada pelas duas instituições de acolhimento desses projetos (entidades do terceiro setor), pela coordenação efetiva de cada um dos dois projetos locais em estudo, e pela implementação técnica dos projetos desenvolvida pelas equipas. Assim sendo, considerou-se como ponto de partida a informação recolhida e analisada sobretudo na fase mais intensiva de recolha de dados, referente: i) a duas entrevistas individuais, realizadas com as responsáveis das duas instituições gestoras do PI, uma no norte, outra no sul do país; ii) a duas entrevistas individuais, realizadas com as coordenadoras dos dois projetos locais do PI estudados; iii) a três entrevistas individuais realizadas com técnicos desses projetos locais do PI, situado um no norte e outro no sul do país. As duas instituições gestoras obedecem aos critérios prévios de seleção dos projetos locais pelo PI, sendo entidades do terceiro setor caraterizadas por desenvolverem um trabalho de intervenção comunitária em contextos de maior vulnerabilidade social, estando localizadas em espaços contíguos a bairros de habitação social, com fenómenos de exclusão social identificados e sobre os quais visam a intervir.

Por motivos de anonimato, os concelhos, ambos do litoral, nos quais se realizam esses dois projetos locais do PI, não são referidos, tendo-se optado por mencionar apenas que se trata de um projeto situado no norte e outro no sul do país. Cada projeto local que é aprovado em sede de candidatura ao PI tem apenas uma entidade gestora, e em cada uma dessas entidades do terceiro setor está afeto desde o início um único responsável. Portanto, para o caso das duas entrevistas individuais realizadas em cada uma das instituições gestoras não se aplicaram critérios de escolha dos entrevistados, o mesmo sucedendo com as duas entrevistas individuais realizadas com as coordenadoras de cada projeto local, dado que se trata de um lugar definido logo em sede de candidatura e uninominal. Para a escolha dos técnicos das equipas a entrevistar tomou-se em conta a sua participação em tempo integral e a sua integração na equipa desde o início da aprovação e implementação do projeto. Todos os entrevistados são diplomados com uma licenciatura em ciências sociais ou educacionais.

As sete entrevistas efetuadas foram gravadas e realizadas no espaço onde decorrem os projetos locais, tendo sido alvo de uma análise de conteúdo estrutural (MAROY, 1997) em que se obtiveram frequências relativas a temas específicos e em que foi favorecida a associação entre os temas identificados. Por outro lado, foi usada a análise de discurso (BACCHI, 2000; TITSCHER et al., 2000) na decomposição do Relatório de Avaliação Externa do PI 2010-2012, do $2^{\circ}$ Relatório Intercalar de Avaliação Externa do PI, no exame da legislação afeta à criação e renovação sucessiva desse programa, no estudo de trinta e três propostas de práticas, e também no escrutínio dos textos da Revista InovAção.

A análise teve em conta duas hipóteses de trabalho: i) essa inovação sociopolítica suscita leituras (e interrogações) que visibilizam a sua congruência com 
tendências integrantes da matriz de regulação social neoliberal (individualização; resolução de problemas e pedagogização; localização); ii) essa política pública contém sinais e corresponde a aspirações e aproximações para "aumentar o compromisso social com a educação, acolhendo e apoiando iniciativas de famílias, de associações, de poderes locais ou de professores, que se desenvolvam num quadro de abertura e de integração de todas as crianças" [e jovens], abrindo possibilidades em torno de "um espaço público da educação" (NÓVOA, 2002, p. 238).

Interessou-nos, então, explorar algumas dimensões do objeto de estudo, designadamente: (i) identificar modos como são trabalhados fora da escola, por referência à escola, a educação, escolar e não escolar, o fracasso e o abandono escolares; (ii) as perspetivas e cursos de ação dos atores envolvidos, com destaque para os técnicos; e (iii) a questão da inserção escolar como problema de inclusão social.

\section{QUADRO TEÓRICO}

Neste estudo, a educação, o Estado e a governação são perspetivados como relações e processos sociais, isto é, como terrenos de práticas sociais, conflituais e contraditórias, em que têm lugar a ação e o enfrentamento políticos. Nesse sentido, considera-se que as formas de governação atualmente observáveis: (i) verificam a reconstituição e reorientação e não a redução da centralidade da ação, do papel e do poder do Estado; (ii) reordenam a distribuição de poder entre as escalas supra e subnacional e (iii) se relacionam ainda com movimentos e aspirações sociais e reações e respostas de baixo para cima, no sentido de ampliar a participação democrática e a transparência na administração e no governo (DALE, 2005).

O debate em torno das reformas do Estado e das políticas públicas prossegue nas últimas quatro décadas procurando compreender e explicar as mudanças que paulatinamente vêm contribuindo para a constituição de um novo regime sociopolítico nas sociedades ocidentalizadas, organizadas como democracias representativas que construíram Estados de Bem-estar. Nesse cenário, a problemática da governação, entendida como matriz sociopolítica de regulação social (neoliberal?) em processo de imposição, tem vindo a ser formulada como resposta "ao diagnóstico da crise das democracias”, de legitimidade e de governabilidade, sob a tendência de hegemonia do programa tematizado a partir da última (SOUSA SANTOS, 2005). As transformações entretanto dinamizadas traduzem-se em formas inéditas de envolvimento do Estado na provisão de bem-estar e de direitos sociais e humanos básicos, como a educação, ao mesmo tempo que constituem novos contextos, desenvolvimentos e protagonistas de ação e luta políticas que a teoria e investigação sociais devem apreender. Nesse sentido, as propostas e modalidades de governação podem ser posicionadas, a partir do significado político e das consequências que produzem, segundo parâmetros de justiça social e educacional.

Desde esse prisma, as políticas, discursos e práticas manifestam-se sob versões neoliberais hegemónicas ou segundo concretizações contraditórias, 
fragmentárias ou ambivalentes, o que suscita um conjunto de interrogações em torno das práticas de democracia e da noção de justiça social e educacional. Adota-se a perspetiva de que a justiça como redistribuição e como reconhecimento cultural já não basta para acudir à complexidade das relações sociais, políticas e culturais do mundo atual, pelo que se propõe que a dimensão política da representação, isto é, a justiça como paridade de participação esteja também presente, e dê lugar, na linha de Fraser (2007) a uma justiça democrática “pós-westfaliana”. Assim sendo, as políticas públicas e as organizações educativas são examinadas na perspetiva da justiça educacional e das medidas educativas que hipoteticamente a acolhem e da compreensão daquelas como fóruns públicos, promotores de convivência democrática, abertos à participação, à contestação e ao debate, ao compromisso com a justiça social global, o que significa uma preocupação clara com o bem comum e com a procura de igualdade de oportunidades educativas e de vida.

Por outro lado, a adoção (o 'regresso') da Educação e Aprendizagem ao Longo da Vida (EALV) como política axial, ocorre, na União Europeia (UE) como em Portugal, na segunda metade da década de 1990, e mais determinadamente desde 2000 no quadro da Estratégia de Lisboa, num contexto sociopolítico favorável quer à desarticulação da educação como direito social e humano envolvido com a formação dos sujeitos e das comunidades, quer à sua tematização como bem de consumo privado, individual e objeto de relações de troca (LAVAL; WEBER, 2002). Não raro, a manutenção do envolvimento do Estado no campo educacional assume formas que acentuam a sua desvinculação quanto às dimensões distributivas e democratizantes das políticas sociais públicas e aos interesses e demandas a que estas respondem.

Não obstante, como sublinham Clarke e Newman (1997), a dispersão do poder, tarefas e responsabilidades do Estado, sob coordenação gestionária, produz o efeito dual de capacitar e disciplinar os agentes envolvidos na provisão de bem-estar, multiplicando os contextos de decisão e incrementando os potenciais focos de resistência e conflito. Desse modo, regista-se a instabilidade dos resultados das reformas do Estado gestionário, bem como possibilidades contraditórias na matriz da governação com desenvolvimentos em múltiplos e incertos sentidos políticos.

Nesse quadro, o Estado cria uma margem de manobra acrescida para atuar de forma estratégica e seletiva, através de modalidades de individualização (favorecendo soluções biográficas) e localização (respostas locais), face a problemas sociais (sistémicos), para inibir ou estimular a inovação social, quer progressiva, quer regressiva, nas margens dos sistemas e transfronteiriça às instituições.

Field (2000) e Hake (2006) salientam a ambivalência como um traço importante das formações sociais da modernidade tardia: um acrescido potencial de produção de exclusão social e de ameaças à coesão social (desenvolvendo "sociedades um terço/dois terços") conjuga-se com a emergência de novas formas de participação social e de formação de identidades; do mesmo modo, a fixação ressentida de identidades tradicionais em comunidades ancestrais (re)imaginadas, 
convive com o desenvolvimento de processos de individualização. Estes são sustentados por condições favoráveis à multiplicação das oportunidades de escolha, mas também de opções compulsivas e situações de risco obrigatoriamente carregadas pelos indivíduos como decorrentes de decisões suas (BECK, 1992; GIDDENS, 1992).

Nesse contexto, a educação é um espaço dinâmico de relações e processos sociais, um terreno de luta política em curso, de embates e pactos políticos provisórios, de inclusões e exclusões (ALMEIDA, 2017). A discussão de dados que se segue explora o caso em estudo do PI; discute-se que intervenções se desenvolvem, porquê, com quem e com que resultados e sentidos, problematizam-se orientações e práticas e questiona-se a fabricação dos contornos do espaço educacional (SEDDON, 2014) através dessas intervenções dinamizadas por entidades sediadas na comunidade.

\section{PERSPETIVAS E CURSOS DE AÇÃO: COMPROMISSO ALARGADO, INTERVENÇÃO FOCADA NOS INDIVÍDUOS...}

\section{INDIVIDUALIZAÇÃO E LOCALIZAÇÃO DOS PROBLEMAS SOCIAIS}

De acordo com os normativos que, entre 2001 e 2015, estabelecem o Programa InovAção, o seu público-alvo é constituído por crianças e jovens em idade escolar, entre os seis e dezoito (até vinte e quatro) anos. Entendidos em tempos como sujeitos de formas de resistência cultural à escola (WILLIS, 1977), passaram a ser definidos como públicos em risco, que podem constituir riscos para as escolas e as comunidades (ROBERTSON; DALE, 2002, p. 472). A intervenção dirige-se aos indivíduos, encarados como sujeitos em situação, de facto ou potencial, agravada de risco social, cujo itinerário biográfico envolve ação e opções. Se pode não estar em questão a natureza multidimensional, ou mesmo sistémica, do risco, também não se colocam expressamente o seu caráter societal, a sua origem estrutural ou a necessidade de uma resposta institucional e global. Se, em 2001, a fórmula usada para definir o contexto da intervenção era "bairros mais vulneráveis" e “contextos socioeconómicos desfavoráveis” e, em 2004, se refere também “contextos socioeconómicos mais desfavoráveis e problemáticos", desde pelo menos 2006 se enuncia como finalidade do programa "promover a inclusão social de crianças e jovens provenientes de contextos socioeconómicos mais vulneráveis". Se, em 2001, se reconhece o défice de recursos e de respostas institucionais e se preconiza o seu reforço,

[...] é necessário, designadamente, que a polícia, a justiça, a segurança social, a saúde, a educação, as autarquias e as entidades da sociedade civil consigam chegar a esses 
Progressivamente a definição das coordenadas do programa tenderá a elidir a dimensão sistémica (económica e política) dos problemas, para reter antes de mais a sua localização e individualização. As práticas e, sobretudo, as regras de funcionamento institucional (da escola, do mercado de trabalho, etc.) permanecem em boa medida excluídas do mandato, da capacidade e do âmbito do Programa como política pública (DALE, 1989). As respostas (mesmo se comunitárias) que a intervenção propõe construir são focadas nos indivíduos, crianças e jovens, e na dimensão biográfica dos seus percursos; isto é, o programa de intervenção procura reforçar os recursos cognitivos, emocionais, reflexivos, de tempo que podem influenciar as decisões, as orientações, os cursos de ação, as estratégias e interpretações dos sujeitos, dos seus grupos de pares e famílias - numa palavra, a dimensão biográfica dos seus itinerários escolares (CASAL, 2003)4. Estes são entendidos como processos (SALVÀ-MUT; OLIVER-TROBAT; COMAS-FORGAS, 2014), que envolvem dimensões de individualização e escolha compulsiva (BECK, 1992; GIDDENS, 1992). Nesse sentido, uma tónica forte do Programa é a construção de soluções (ou respostas) biográficas para problemas sistémicos (BECK, 1992) como o fracasso e abandono escolares, o desemprego ou a pobreza; não é que não sejam reconhecidas as dimensões estruturais e institucionais destas problemáticas; é que, como acima se elucida, elas são elididas enquanto foco de intervenção. No entanto, essa delimitação não impede que os responsáveis do Projeto assumam finalidades de ação para questionar e instabilizar relações de poder, que se colocam como barreiras à participação na aprendizagem e na escola. É nesse fio da navalha que se desenrola a ação do Programa. É enquanto destino individual que a pobreza e a exclusão são batalhadas, elegendo a "inserção" e "a carreira escolar" como eixos decisivos daquela trajetória (AAVV, 2013, p. 40, 45).

\section{A CAPACITAÇÃO INDIVIDUAL COMO CONSTRUÇÃO COLETIVA}

As entrevistas com os atores no terreno sugerem uma constelação de sentidos em que se cruzam as perspetivas de que se trata de: agir na comunidade, em contexto de proximidade; construir relações de confiança, com um público-alvo claro constituído por indivíduos identificados e com itinerários biográficos em aberto; mobilizar recursos suportados por um compromisso interinstitucional alargado; procurar a inclusão escolar como finalidade, enquanto recondução de um percurso académico à normalidade portadora (ou não?) de novas oportunidades.

\footnotetext{
4 A Resolução do Conselho de Ministros (2001), que criou o Programa InovAção, contextualiza-o no quadro mais vasto das políticas sociais do Estado, clarificando a natureza de que se reveste: "O presente programa não cuida das políticas universais que tem desenvolvido, como as de combate à exclusão (exemplo: rendimento mínimo garantido) ou de equidade e de igualdade de oportunidades no acesso à educação (diversificação curricular, apoio específico a grupos carenciados), mas sim, em articulação com as medidas de política social global e as medidas universais, de formular medidas políticas seletivas para jovens que vivem em bairros vulneráveis [...], de modo a aproximá-los de medidas de formação pessoal, escolar e profissional" (PORTUGAL, 2001, p. 2). Esse enquadramento desaparece nos textos normativos seguintes, mesmo se aquelas políticas sociais e educativas se mantêm, à medida que o Programa alarga o seu âmbito de intervenção, em termos de problemáticas, de públicos e geográficos:
} 
Nesse quadro, é possível problematizar a relação de tais orientações e práticas com a mobilização de tecnologias positivas de poder, em que esses processos se revestem de um sentido acrescido (PAGNI, 2017, p. 259 e ss.).

A intervenção é formal e declaradamente dirigida a indivíduos sinalizados como vivendo situações de risco social que se entende poderem ser alteradas (DENTZ; DIAS DA SILVA, 2017):

[...] uma criança vem para o projeto, é feita essa ficha e, anualmente ou, neste caso, semanalmente, é feita a avaliação daqueles critérios para ver se a criança já evoluiu ou não. Se ela tiver evoluído ao ponto de já não apresentar esses problemas ditos sociais ou escolares, ela passa de [destinatário] direto para indireto porque é conforme esses fatores de risco [...] É criado um plano individual e, a partir do momento em que ele consegue ultrapassar estes problemas-base, transita de [destinatário] direto para indireto. (Coordenadora, projeto Sarande, E15)

Trata-se de envolver os sujeitos em experiências educacionais organizadas e orientadas que lhes permitam beneficiar de recursos adicionais, de interações enriquecedoras, de oportunidades para construir comportamentos e atitudes desejáveis.

[...] portanto, temos salas de promoção de estudo mais do que uma vez por dia; depois, semanalmente, temos os treinos de futsal porque eles agora como estão federados têm que treinar quatro vezes por semana; temos a percussão; temos o espaço de inclusão digital que está sempre aberto e temos sempre consequentemente aulas de ICT para vários grupos de várias idades; temos a escola virtual para dar apoio também às crianças e jovens [...] e temos o @TV que é o trabalho para a construção de filmes, etc, a gente chama-lhe @TV, mas não fomos nós que escolhemos foram eles [...] A Express'arte, a gente chama-Ihe expressão através da arte é feita uma vez por semana, é feito dentro do autocarro nas manhãs [...]; o Visitas às profissões, embora seja, se não estou em erro, quinzenal portanto o objetivo é que eles possam ir, por exemplo, conhecer os bombeiros, possam ir à PSP, pronto fazer assim um bocado orientação profissional [...]; o Liga-te é também de orientação vocacional e é também regular. (Coordenadora, projeto Sarande, E15)

Assim, aposta-se na capacitação individual para aprender e responder com sucesso ao ofício de aluno (PERRENOUD, 1995): "Promoção do sucesso escolar, 
dentro ou fora da escola, através do desenvolvimento de competências pessoais, sociais e cognitivas por via da educação formal e não formal" (PORTUGAL, 2012, p. 4280). De acordo com o relatório de avaliação externa, no que toca a resultados quanto à inserção escolar,

\begin{abstract}
Para estes [bons] resultados convergem diversas atividades como o apoio escolar, a escola virtual ou programas de enriquecimento cognitivo mas também outras dimensões de intervenção, em particular a promoção de competências pessoais e sociais, onde são trabalhadas competências como a confiança, a autoestima, a responsabilização e autonomia que em muito contribuem para o investimento escolares. (AAVV, 2013, p. 170)
\end{abstract}

Trata-se de abordagens cognitivas e terapêuticas, dirigidas ao comportamento, direcionadas para melhorar o desempenho dos estudantes (HALPIN et al., 2004, p. 201). Como nota Power, algumas das atividades mencionadas constituem "recursos extra" que proporcionam a essas crianças e jovens condições de aprendizagem "mais aproximadas" daquelas de que outros "estudantes mais favorecidos beneficiam” (2008, p. 30). Estão referidas naquele enunciado, quer a compensação de défices institucionais da pedagogia (tempo e/ou atividades de aprendizagem), quer dimensões envolvidas com a gestão do eu (self management), das escolhas e do risco individualizado (ROBERTSON; DALE, 2002, p. 472) ou ainda com a aprendizagem e construção de competências biográficas (HAKE, 2006). Como questionam os autores de um relatório europeu recente sobre políticas de educação prioritária, se a educação pode compensar desvantagens e dificuldades diversas dos alunos, não seria expectável que tal pudesse ser logrado pelo sistema educativo (FRANDJI et al., 2009, p. 46)?

Porventura, as perspetivas dos atores apontam uma matriz de intervenção que, como se documenta, partilha de pressupostos de individualização e localização dos problemas sociais e propõe respostas de pendor remediativo e adaptativo. A mobilização de recursos acrescidos para enriquecer as propostas educativas, a dimensão interativa e coletiva das experiências são uma constante no relato dos técnicos sobre práticas do projeto e os seus horizontes:

[O grupo de percussão] é uma atividade importante também para eles terem um bocado de disciplina e também um bocado de espírito de grupo, porque ali eles funcionam em grupo, pode haver um que toque muito bem e outro que não toque e eles têm que controlar ali um bocado os egos e é bom por causa disso, é uma atividade engraçada para eles fazerem; depois, também lhes dá destrezas e também competências musicais. (Técnico, projeto Sarande, E17, 1-2) 
[...] então pensamos em formar uma equipa de futsal federada onde eles tinham que ter outras responsabilidades, entregar-Ihes responsabilidade [...] difícil no início porque nenhum dos miúdos estava preparado para tal e neste momento estão realmente a encaixar no que nós queremos; realço também a atividade das férias que foi a atividade Sarandar em que os nossos jovens e os nossos pequeninos ajudaram na limpeza do bairro e foram dois dias de desgaste e os miúdos até os mais pequeninos estiveram lá a ajudar e a participar [...]; temos a Assembleia de jovens, em que eles ajudam a decidir ou o que é que gostavam de fazer, porque a nossa opinião... por exemplo, "vamos apanhar castanhas" se eles não gostarem também não vale a pena fazer. (Técnico, projeto Sarande, E18)

[...] temos previsto para o final do ano a criação de uma associação juvenil com os jovens. (Coordenadora, projeto Sarande, E15)

Nessa perspetiva, a organização da ação parece inspirar-se numa abordagem de resolução de problemas, remetidos para o foro individual e local; isto é, as instituições (a escola, a economia, o mercado de trabalho...) não chegam a ser desafiadas ou questionadas. No entanto, a pretendida normalização das biografias e dos contextos de vida aparece enquadrada num processo de reforço de interdependências, de estimulação da responsabilidade e construção coletivas, sustentado por um compromisso alargado que excede em muito quer a equipa técnica, quer a instituição escolar, ainda que as não dispense.

\section{UM COMPROMISSO ALARGADO... NO TEMPO}

[...] principalmente a relação que temos com as comunidades, com os miúdos já é de muita confiança e uma vez que há confiança o trabalho é muito mais bem feito, quer a nível escolar, quer a nivel cívico também, de cidadania, conseguimos ver a evolução em muitas crianças e jovens, mas parte tudo da base da confiança, se não houver confiança não é possivel. (Técnico, projeto Sarande, E17, 10)

[...] acho que atualmente elas são todas muito presentes ... a junta de freguesia, que me esqueci de mencionar, também estão sempre presentes nas reuniões, mesmo em questões financeiras, agora pagou os exames de medicina desportiva dos miúdos, mas lá está isto também já é um trabalho de 5 anos e, parecendo que não, faz diferença desde o primeiro ano até agora... [...] a equipa de futsal, que foi feita inteiramente em parceria, portanto corre muitíssimo bem e 
acho que é um excelente exemplo, em termos financeiros e logísticos [...] Sim, para o ano a equipa irá continuar, julgo que sim, o grande objetivo da construção desta equipa era esse, era que continuasse, era primeiro testar os parceiros e garantir que só iríamos formar a equipa quando os parceiros estivessem mesmo preparados para a assumirem. (Coordenadora, projeto Sarande, E15)

Nesse sentido, a equipa técnica do projeto, o enraizamento e a capacitação comunitários, a interação de proximidade e a construção da confiança, bem como o compromisso interinstitucional alargado constituem recursos ao serviço da construção desse envolvimento e enriquecimento da experiência individual e coletiva que se espera possam contribuir para, e construir a inclusão e a normalização da biografia individual, superando ou atenuando o risco social que sinalizava cada sujeito. Desse modo, as práticas evocadas podem contribuir para reforçar "recursos que estão embutidos (embedded) nas relações familiares e na organização comunitária e são benéficos para o desenvolvimento cognitivo e social dos jovens” (BASIT, 2012, p. 130).

A questão que se coloca não incide sobre o ângulo de intervenção e o foco das respostas construídas (os sujeitos e os percursos individuais), mas sobre as implicações da elisão do quadro societal dos problemas (sistémicos, económicos, políticos, culturais) e do quadro global das respostas necessárias (políticas económicas e sociais, universais e seletivas) (cf. PARSONS, 2016). Como sugere Roger Dale, as limitações autoimpostas e aceites por uma abordagem dirigida às manifestações de um pequeno número de variáveis impedem severamente a sua capacidade de resolver problemas (DALE, 1986).

No entanto, os projetos integrantes do Programa InovAção enunciam massivamente problemáticas socioeconómicas como fundamentação da intervenção: pobreza (89,4\% dos projetos), défice de condições sanitárias, equipamentos sociais e cuidados de saúde primária (75,8\% dos projetos) (AAVV, 2013, p. 31). A análise do relatório de avaliação externa da $4^{\text {a }}$ fase do Programa sugere que as ações desenvolvidas pelos projetos decorrem do reconhecimento do insucesso e o abandono escolares como realidades multidimensionais, mas naturalmente se assume os pressupostos referidos para intervir nos interstícios dos percursos individuais, nas margens institucionais e nas comunidades periféricas. É esse o lugar da ação do Programa.

\section{A DIMENSÃO INSTITUCIONAL: EXCLUÍDOS DO INTERIOR OU UMA OUTRA EDUCAÇÃO? ${ }^{5}$}

Por outro lado, o esforço para alargar as oportunidades institucionais, para construir respostas educativas que ampliem opções e oportunidades de vida 
raramente parece exceder as fronteiras das vias remediativas, profissionalizantes, particularistas, voltadas para públicos sinalizados, que deixa intocados o ensino regular, a via nobre, a organização pedagógica da escola, o currículo, a gramática da escola (TYACK; TOBIN, 1994).

[...] temos os cursos vocacionais, que foi um projeto piloto o ano passado, o ano passado letivo com a Escola Profissional [...], que era só uma turma o ano passado, mas que neste momento já são três turmas de cursos vocacionais, temos os [cursos do] Programa Integrado de Educação e Formação. (Coordenadora, projeto Cirandarte, E5)

Em consequência, não são desafiadas as barreiras institucionais que dificultam o acesso e o domínio do conhecimento poderoso (YOUNG; MULLER, 2010), por parte desses jovens, e fabricam o insucesso e abandono escolares. Mesmo quando bem-sucedido nos resultados, o Programa dificilmente chega a desafiar os processos que produzem desigualdades escolares: porque o sucesso escolar desses públicos continua muitas vezes a passar por percursos alternativos ao ensino regular. ${ }^{6}$

Como se afirma numa recente revisão crítica da literatura sobre abandono escolar, a economia, a política, a sociedade em geral são frequentemente excluídas do quadro global do debate e análise da intervenção socioeducativa para superar o insucesso e abandono escolares e mesmo a organização do sistema educativo tende a permanecer subexplorada quanto ao seu envolvimento com esses processos. Os autores argumentam de seguida que,

[...] enquanto os diplomas alternativos têm sido, e continuam a ser, considerados como respostas adequadas, senão ideais, para o abandono escolar precoce, eles não colocam os titulares de diplomas alternativos no mesmo nível que os graduados do ensino secundário, face ao mercado de trabalho e, assim, falham em resolver os problemas que aí encontra o jovem que abandonou precocemente a escola. (DE WITTE et al., 2013, p. 26)

Assim sendo, como questiona Broccolichi (2009, p. 185): a prioridade desse programa é prevenir a exclusão, aumentar a inserção escolar, combater e reduzir o insucesso e abandono escolares ou torná-los aceitáveis, procurando

6 Os indicadores globais do Relatório de Atividades de 2014 do PI apresentam uma taxa de $74 \%$ de sucesso escolar dos participantes em todos os projetos e a última avaliação externa corrobora esses resultados e destaca ainda a diminuição do absentismo e do abandono escolares e crescente interiorização da importância da escola (AAVV, 2014, p. 31). Por outro lado, é, no mesmo relatório, reportado cerca de 1900 reintegrações escolares, no ano letivo 2013-14, sinalizando contínuas dificuldades no encaminhamento para respostas alternativas, tipo PIEF [Programa Integrado de Educação e Formação] e cursos de dupla certificação, admitindo-se que os (à época) novos CQEP [Centros para a Qualificação e Ensino Profissional] vieram criar novas expectativas nesse campo (AAVV, 2014, p. 37) 
gerir as desigualdades? ${ }^{7}$ Por outro lado, frequentemente os jovens relatam que nesses percursos encontram a experiência, a mobilização e o sentido de aprender (CHARLOT, 1999; SÁ; ANTUNES, 2012); controversa, a questão impõe-se: são essas respostas educativas um caminho para derrubar as barreiras à aprendizagem que encontraram no ensino regular ou apenas as tornam invisíveis (YOUNG; MULLER, 2010)? Se assim for, não constituem essa outra educação procurada pelos jovens, mais um lugar de exclusão, suave mas nem por isso menos efetiva, pelo confinamento (MOREIRA, 2008, p. 218) a que, de uma outra forma, mesmo se acompanhada pelo contentamento dos próprios, acaba por submeter os seus públicos?

\begin{abstract}
Eram jovens ciganos que frequentavam a escola [...]. Vieram para aqui durante 14 meses fazer o projeto com professores no âmbito das artes (na área da dança, do teatro) [...] O projeto nasceu cá, nasceu na instituição [...] Sim. Foi tratado antes na Câmara, depois da aprovação da candidatura fomos ter com as escolas, eles foram muito bem aceites, muito bem acompanhados pela escola e por nós. (Responsável de IPSS promotora do projeto Sarande, E1)
\end{abstract}

Ou não... Nos interstícios, nas margens, nas periferias, talvez se distingam práticas de possibilidades de uma outra educação. Lá onde a matemática se tornou acessível, lá onde o teatro e a música forçaram as portas da escola ou criaram pontes com a associação e a comunidade e soltaram vozes. Porventura efémeras pontes e vozes... porventura transitórias práticas e possibilidades. Numa perspetiva de justiça socioeducacional, a intervenção face a desigualdades em educação através da educação profissional pode traduzir-se na ampliação de oportunidades institucionais; importa examinar as condições efetivamente existentes no terreno para realizar a ação educativa e pedagógica e interrogar o seu impacto nas oportunidades de vida dos sujeitos.

\title{
ENVOLVIMENTO E CONTROLO SOCIAL DAS FAMÍLIAS
}

Por outro lado ainda, desenvolve-se uma intervenção que: (i) tende a "pedagogizar a criança na sua totalidade e mesmo a família” (POWER, 2008, p. 34), encarando-as como "sistemas de défices" (BERNSTEIN, 1982); (ii) é fundada em perspetivas ortopédicas e pressupostos carencialistas sobre famílias economicamente desfavorecidas. De forma elucidativa, o relatório de avaliação externa regista, por parte de jovens destinatários entrevistados, "um inequívoco reconhecimento" do papel dos laços familiares nos momentos que consideram felizes, acrescentando que "é a união familiar a sobrepor-se à desestruturação familiar" (AAVV, 2013, p. 289).

7 O autor coloca a questão face às políticas de educação prioritária desenvolvidas na Europa desde os anos sessenta (cf. FRANDJl et al., 2009). 
O Programa partilharia uma "teoria da ação" que supõe que a desvantagem educativa resulta de dificuldades dos alunos e das famílias a que a escola fracassou responder (FRANDJI et al., 2009, p. 48). Integrando a área de intervenção dirigida à Inclusão escolar e educação não formal, a "corresponsabilização dos familiares no processo de supervisão parental” é referida na avaliação externa do programa como "foco prioritário”, já que 90,9\% dos projetos (120) apontam “dificuldades de acompanhamento dos percursos escolares pelas famílias”. Assim,

\begin{abstract}
A maioria dos discursos sobre as famílias tem uma conotação negativa: a falta de competências parentais e a falta de acompanhamento escolar dos seus educandos assumem um peso crucial no despoletar ou na manutenção das problemáticas das crianças e jovens. [...] Sucedem-se pois atividades que pretendem um diálogo com as famílias e gerar uma proximidade entre escola, projecto e família. (AAVV, 2013, p. 45-46)
\end{abstract}

O alvo dessa abordagem terapêutica (POWER, 2008, p. 34) é formar bons pais e boas mães e trazer as famílias à colaboração com a escola e coexiste com a mobilização de recursos e dinâmicas familiares e comunitárias como práticas de afirmação e criação culturais e de participação comunitárias.

\title{
FINALIZANDO - NOVAS LÓGICAS DE GESTÃO PÚBLICA E DESIGUALDADES: TENSÕES E AMBIVALÊNCIAS
}

Procurámos discutir duas hipóteses de leitura do caso em estudo de uma política socioeducacional pública (o Programa InovAção): a prevalência de tendências integrantes da matriz sociopolítica de regulação social neoliberal (individualização, pedagogização e localização) e/ou a aproximação a aspirações e práticas de construção de um espaço público de educação, tendo em vista a abertura e integração de todas as crianças, mobilizando um compromisso social com a educação envolvendo múltiplos constituintes, das famílias aos poderes locais, aos professores ou cidadãos associados e organizados. A análise apresentada sugere que a primeira vertente não esgotará a ação do Programa: a dinamização de diversas atividades socioeducativas, o envolvimento de segmentos das populações nessas propostas, o fomento de modalidades de ação coletiva mais ou menos organizada (grupos, redes, associações) suscita questionamentos sobre os contornos de outra vertente do Programa que importa compreender.

No Programa InovAção, o fracasso e abandono escolares aparecem como realidades multidimensionais, "análise na qual trazer o entorno social permite recolocar a questão da desigualdade social como problema posto ao trabalho da escola" (ALMEIDA, 2017, p. 364). No entanto, aqueles processos são trabalhados, no plano da microintervenção comunitária, fundamentalmente enquanto componente do itinerário biográfico dos indivíduos. Nesse sentido, são tratados como 
foco de orientações e opções individuais, para o que contribuem as competências dos sujeitos para interpretar e agir nas situações referentes à vida escolar, incluindo os recursos cognitivos, emocionais e outros para responder às expectativas da instituição. Por isso, a intervenção se dirige a capacitar os jovens nesses sentidos, procurando reforçar a mobilização para a escola e para aprender. Esse esforço e investimento na capacitação individual articula-se com a procura de respostas institucionais frequentemente construídas como alternativas face aos percursos formativos de referência. São as vias profissionalizantes que interpelam o centro do sistema, quer sobre a sua omissão quanto à educação profissional, remetendo-a para o lugar de uma via remediativa, quer sobre a aceitação das desigualdades de aprendizagens dos diversos públicos. Por último, o trabalho com as famílias tende a designá-las como deficitárias a diversos títulos e alvo de intervenção compensatória e adaptativa, ao mesmo tempo que se procura o seu envolvimento em atividades de natureza lúdica, cívica ou criativa em sentidos mais mobilizadores e participativos.

Trata-se de uma política cirúrgica, como se viu, quer quanto às populações, quer quanto aos domínios de intervenção: os indivíduos; as dimensões biográficas de itinerários escolares problemáticos; as dimensões institucionais escolares, tendencialmente reduzidas às respostas alternativas/remediativas e não-regulares; as famílias, nas suas dimensões de organização e funcionamento como parceiros escolares.

As tensões, contradições e ambivalências manifestam-se no quadro sociopolítico e nas condições de intervenção no terreno: assumindo pressupostos individualizantes e carencialistas e objetivos de capacitação para os indivíduos, as famílias e as comunidades, mobilizam respostas institucionais remediativas e desenvolvem atividades de educação não-formal e animação socioeducativa comunitária como recursos para dinamizar o envolvimento e a participação. Tratase de localizar problemas sociais e escolares, elidindo e iludindo a sua dimensão sistémica e institucional, e/ou de uma aproximação à construção do espaço público de educação (NÓVOA, 2002)?

\section{APROXIMAÇÕES À CONSTRUÇÃO DO ESPAÇO PÚBLICO DE EDUCAÇÃO: SINAIS}

Como bem nota Gomes (2012), desde há várias décadas os sociólogos estudam a omnipresença da relação pedagógica nos diversos domínios da vida social, enquanto forma de ação pedagógica em favor do controlo social através da modelação dos comportamentos, dos afetos, das aspirações em sentidos previstos. Nesse sentido, a mesma autora aponta a sociedade pedagógica estudada por Beillerot (1985) e a sociedade totalmente pedagogizada discutida por Bernstein (2001) cerca de 15 anos depois, como formulações e ferramentas concetuais para a compreensão dessas relações e processos sociais. Ao mesmo tempo, propõe que a discussão de António Nóvoa em torno do espaço público de educação suscita um questionamento alternativo a práticas sociais de fabricação do espaço educacional (SEDDON, 2014), a nosso ver pertinente para refletir as observações que fomos registando em torno do programa InovAção. 
As perspetivas e cursos de ação testemunhados pelos atores, sobretudo técnicos do terreno, permitem apreender tensões e contradições entre, por um lado, uma matriz de intervenção que declaradamente individualiza o risco social e localiza problemas sociais, enquanto fomenta repertórios de ação vocacionados para estimular experiências de construção e decisão coletivas. As práticas e orientações enunciadas evocam interdependências, responsabilidades, processos e instrumentos de ação coletivos dos sujeitos, bem como compromissos sociais alargados na ação local em torno da educação. Nesse sentido, sugerimos que as perspetivas, orientações e práticas observadas indiciam a fabricação de um espaço educacional cujo sentido político é incerto e atravessado de tensões e contradições; nesse quadro, a escola é valorizada como parceira para uma resposta de integração escolar ao problema de exclusão social dos sujeitos. As questões que se levantam, sobre o potencial de tais arranjos institucionais, contextos e práticas se constituírem como aproximações, contraditórias e precárias, a um espaço público de educação em tensão com aquela regulação social neoliberal, são acompanhadas por interrogações sobre outras dimensões da intervenção. Designadamente é pertinente perguntar em que medida são construídas práticas socioeducativas suscetíveis de desafiar relações e processos sociais que, no âmbito de instituições poderosas como a escola e o mercado de trabalho, tendem a excluir os públicos envolvidos.

\title{
REFERÊNCIAS
}

AAVV. Avaliação Externa do Programa InovAção 2010-2012. Lisboa: ISCTE/DINÂMIA-CET, 2013.

\begin{abstract}
AAVV. Avaliação Externa do Programa InovAção ( $5^{a}$ edição) - 2. ${ }^{\circ}$ Relatório Intercalar. Porto: Centro de Estudos dos Povos e Culturas de Expressão Portuguesa/Faculdade de Ciências Humanas/Universidade Católica Portuguesa, 2014.
\end{abstract}

ALMEIDA, Luana. As desigualdades e o trabalho das escolas: problematizando a relação entre desempenho e localização socioespacial. Revista Brasileira de Educação, v. 22, n. 69, p. 361-384, abr.jun. 2017.

ALONSO, Luís Enrique. Ciudadanía, sociedad del trabajo y estado de bienestar: los derechos sociales en la era de la fragmentación. In: LEDESMA, Manuel Pérez; BENITO, Luis Enrique Alonso (comp.). Ciudadanía y democracia. Madrid: Pablo Iglesias, 2000. p. 159-191.

BACCHI, Carol. Policy as discourse: what does it mean? Where does it get us? Discourse: Studies in the Cultural Politics of Education, v. 21, n. 1, p. 45-57, 2000.

BASIT, Tehmina. 'My parents have stressed that since I was a kid': young minority ethnic British citizens and the phenomenon of aspirational capital. Education, Citizenship and Social Justice, v. 7, n. 2, p. 129-143, 2012.

BECK, Ulrich. Risk Society, towards a new modernity. London: Sage, 1992.

BEILLEROT, Jacky. A sociedade pedagógica. Lisboa: Rés-Editora, 1985.

BERNSTEIN, Basil. A educação não pode compensar a sociedade. In: GRÁCIO, Sérgio; STOER, Stephen. Sociologia da educação II - Antologia: a construção social das práticas educativas. Lisboa: Livros Horizonte, 1982. p. 19-31.

BERNSTEIN, Basil. Das pedagogias aos conhecimentos. Educação, Sociedade e Culturas, Porto, v. 15, p. 9-17, 2001.

BOBBIO, Norberto. O futuro da democracia. Lisboa: Publicações Dom Quixote, 1988. 
BOURDIEU, Pierre; CHAMPAGNE, Patrick. Os excluídos do interior. In: BOURDIEU, Pierre. Escritos de educação. Petrópolis: Vozes, 1998. p. 217-227.

BROCCOLICHI, Sylvain. Lacunes et mésusages dans l'évaluation des PEP. In: FRANDJI, Daniel; PINCEMIN, Jean-Marie; DEMEUSE, Marc; GREGER, David; ROCHEX, Jean-Yves. Comparaison des politiques d'éducation prioritaire en Europe. Rapport scientifique: éléments d'une analyse transversale: formes de ciblage, action, évaluation. Lyon: INRP, 2009. p. 177-191. v. 2.

CASAL, Joaquín. La transición de la escuela al trabajo. In: FERNÁNDEZ PALOMARES, F. Sociología de la educación. Madrid: Pearson Educación, 2003. p. 179-201.

CHARLOT, Bernard. Le rapport au savoir en milieu populaire: une recherche dans les lycées professionnels de banlieue. Paris: Anthropos, 1999.

CLARKE, John; NEWMAN, Janet. The managerial state. Londres: Sage, 1997.

COUNCIL OF THE EUROPEAN UNION. Detailed work programme on the follow-up of the objectives of education and training systems in Europe. Official Journal of the European Communities, 14 Jun. 2002.

CROUCH, Colin. Post-democracy. New York: Polity Press, 2004.

DALE, Roger. A globalização e a reavaliação da governação educacional. Um caso de ectopia sociológica. In: TEODORO, António; TORRES, Carlos Alberto. Educação crítica e utopia: perspectivas para o século XXI. Porto: Afrontamento, 2005. p. 53-69.

DALE, Roger. The state and education policy. USA: Open University Press, 1989.

DALE, Roger. Perspectives on education policy. Milton Keynes: Open University Press, 1986.

DENTZ, Marta Von; DIAS DA SILVA, Roberto Rafael. Estratégias de intervenção do serviço social nas políticas de escolarização: uma análise contemporânea. Educação e Pesquisa, São Paulo, v. 43, n. 3, p. 695-710, 2017.

DE WITTE, Kristof; CABUS, Sofie; THYSSEN, Geert; GROOT, Wim; VAN DEN BRINK, Henriette. A critical review of the literature on school dropout. Educational Research Review, v. 10, p. 13-28, dez. 2013.

EUROPEAN UNION AGENCY FOR FUNDAMENTAL RIGHTS. Roma survey: data in focus. Poverty and employment: the situation of Roma in 11 EU Member States. Luxembourg: Publications Office of the European Union, 2014. http://dx.doi:10.2811/50875

EUROSTAT. Smarter, greener, more inclusive? Indicators to support the Europe 2020 strategy. 2016 edition. Luxembourg: Publications Office of the European Union, 2016. Disponível em: https://ec.europa.eu/info/ strategy/european-semester/framework/europe-2020-strategy_en. Acesso em: 17 fev. 2017.

FERNANDES, José Pedro Matos; ARAÚJO, Alberto Filipe; GARCÍA DEL DUJO, Ángel. Democracia, inteligência e (boa) educação, na perspectiva de John Dewey. Educação e Pesquisa, São Paulo, v. 44, e169625, 2018. Disponível em: http://dx.doi.org/10.1590/s1678-463420170916925. Acesso em: 6 jun. 2018.

FIELD, John. Lifelong learning and the new educational order. London: Trentham Books, 2000.

FONTANA, Andrea; FREY, James. Interviewing: the art of science. In: GUBA, Egon G.; LINCOLN, Yvonna S.; DENZIN, Norman K. (ed.). Handbook of qualitative research. USA: Sage, 1994. p. 361-376.

FRANDJI, Daniel; PRINCEMIN, Jean-Marie; DEMEUSE, Marc; GREGER, David; ROCHEX, Jean-Yves. «EuroPEP» Comparaison des politiques d'éducation prioritaire en Europe. Rapport scientifique: éléments d'une analyse transversale: formes de ciblage, action, évaluation. Lyon: INRP, 2009. v. 2.

FRASER, Nancy. Reframing justice in a globalizing world. In: CONNOLLY, Julie; LEACH, Michael; WALSH, Lucas (ed.). Recognition in politics: theory, policy and practice. Cambridge: Cambridge Scholars Press, 2007. p. 16.

GIDDENS, Anthony. As consequências da modernidade. Oeiras: Celta, 1992.

GOMES, Elisabete X. A cidade como espaço público de educação de crianças: contributos de um estudo de caso. In: CONGRESSO LUSO-BRASILEIRO DE POLÍTICA E ADMINISTRAÇÃO DA EDUCAÇÃO, 6., 2012, Lisboa. Atas [...]. Lisboa: Fórum Português de Administração Educacional, 2012. p. 527-540. 
GUBA, Egon; LINCOLN, Yvonna. Competing paradigms in qualitative research. In: DENSIN, Norman; LINCOLN; Yvonna (ed.). Handbook of qualitative research. USA: Sage, 1994. p. 105-117.

HAKE, Barry J. Late modernity and the learning society: problematic articulations between social arenas, organizations and individuals. In: CASTRO, Rui V.; SANCHO, Amélia V.; GUIMARÃES, Paula (ed.). Adult education: new routes in a new landscape. Braga: Universidade do Minho/Unidade de Educação de Adultos, 2006. p. 31-56.

HALPIN, David; DICKSON, Marny; POWER, Sally; WHITTY, Geoff; GEWIRTZ, Sharon. Curriculum innovation within an evaluative state: issues of risk and regulation. The Curriculum Journal, v. 15, n. 3, p. 197-206, 2004

LAVAL, Christian; WEBER, Louis. Le Nouvel Ordre Éducatif Mondial. OMC, Banque Mondial, OCDE, Commission Européenne. Paris: Nouveaux Regards/Syllepse, 2002.

MAROY, Christian. A análise qualitativa de entrevistas. In: ALBARELLO, Luc; DIGNEFFE, Françoise; HIERNAUX, Jean-Pierre; MAROY, Christian; RUQUOY, Danielle; SAINT-GEORGES, Pierre de. Práticas e métodos de investigação em ciências sociais. Lisboa: Gradiva, 1997. p. 117-155.

MEO, Analía Inés; MILSTEIN, Diana. Programas socioeducativos y regulación del trabajo docente en el nivel secundario. Educação e Pesquisa, São Paulo, v. 44, e160182, 2018. Disponível em: https://dx.doi.org/10.1590/ s1517-9702201703160182. Acesso em: 5 jun. 2018.

MOREIRA, António F. B. A importância do conhecimento escolar em propostas curriculares alternativas. In: CONGRESSO DA SPCE, 9., 2007, Funchal. Actas [...]. Porto: SPCE, 2008. p. 203-219.

NÓVOA, António. O espaço público da educação: imagens, narrativas e dilemas. In: AAVV. Espaços de Educação, Tempos de Formação. Lisboa: Fundação Calouste Gulbenkian, 2002. p. 237-263.

OLSSEN, Mark. Neoliberalism, globalisation, democracy: challenges for education. Globalisation, Societies and Education, v. 2, p. 231-275, 2004. Disponível em: https://doi.org/10.1080/14767720410001733665. Acesso em: 19 out. 2016.

PAGNI, Pedro Ângelo. A emergência do discurso da inclusão escolar na biopolítica: uma problematização em busca de um olhar mais radical. Revista Brasileira de Educação, Rio de Janeiro, v. 22, n. 68, p. 255-272, jan./mar. 2017.

PARSONS, Carl. Ethnicity, gender, deprivation and low educational attainment in England: political arithmetic, ideological stances and the deficient society. Education, Citizenship and Social Justice, v. 11, n. 2, p. $160-183,2016$. DOI $10.1177 / 1746197916648282$

PERRENOUD, Philippe. Ofício de aluno e sentido do trabalho escolar. Porto: Porto, 1995.

PORTUGAL. Presidência do Conselho de Ministros. Resolução do Conselho de Ministros (RCM) 4/2001. Aprova o programa de prevenção da criminalidade e inserção de jovens, denominado "ESCOLHAS". Diário da República Eletrônico. Lisboa: Presidência do Conselho de Ministros, 9 jan. 2001. Disponível em: https://dre. pt/pesquisa/-/search/239016/details/normal?q=Resolu\%C3\%A7\%C3\%A3o+do+Conselho+de+Ministros+n.\%C2\% BA\%204\%2F2001\%2C\%20de+9+de+janeiro. Acesso em: 11 jun. 2014.

PORTUGAL. Presidência do Conselho de Ministros. Resolução do Conselho de Ministros (RCM) 60/2004. Procede à renovação do Programa Escolhas, criado pela Resolução do Conselho de Ministros n. ${ }^{\circ}$ 4/2001, de 9 de Janeiro. Diário da República Eletrônico. Lisboa: Presidência do Conselho de Ministros, 30 abr. 2004. Disponível em: https://dre.tretas.org/dre/171298/resolucao-do-conselho-de-ministros-60-2004-de-30-de-abril. Acesso em: 11 jun. 2014.

PORTUGAL. Presidência do Conselho de Ministros. Resolução do Conselho de Ministros (RCM) 80/2006. Procede à renovação, para o período de 2007 a 2009, do Programa Escolhas, criado pela Resolução do Conselho de Ministros n. ${ }^{\circ}$ 4/2001, de 9 de Janeiro. Lisboa: Presidência do Conselho de Ministros, 26 jun. 2006. Disponível em: https://dre.pt/web/guest/pesquisa/-/search/360114/details/normal?jp=true. Acesso em: 11 jun. 2014.

PORTUGAL. Presidência do Conselho de Ministros. Resolução do Conselho de Ministros (RCM) 68/2012. Procede à renovação, para o período de 2013 a 2015, do Programa Escolhas ( $5^{\mathrm{a}}$ geração), criado pela Resolução do Conselho de Ministros n. ${ }^{\circ}$ 4/2001, de 9 de janeiro. Lisboa: Presidência do Conselho de Ministros, 9 ago. 2012. Disponível em: https://dre.tretas.org/dre/302945/resolucao-do-conselho-de-ministros-68-2012-de-9-deagosto. Acesso em: 10 jun. 2014. 
POWER, Sally. How should we respond to the continuing failure of compensatory education? Orbis Scholae, v. 2, n. 2, p. 19-37, 2008.

ROBERTSON, Susan; DALE, Roger. Local states of emergency: the contradictions of neo-liberal governance in education in New Zealand. British Journal of Sociology of Education, v. 23, n. 3, p. 463-482, 2002.

SÁ, Virgínio; ANTUNES, Fátima. Uma outra educação? Um lugar de exclusão? Sobre os Cursos de Educação e Formação na voz de alunos e professores. In: ALMEIDA, Maria de Lourdes P.; THOMÉ, Nilson. (Org.) Educação: história e política: uma discussão sobre processos formativos e socioculturais. Campinas: Mercado de Letras, 2012. p. 57-100.

SALVÀ-MUT, Francesca; OLIVER-TROBAT, Miquel; COMAS-FORGAS, Rubén. Abandono escolar y desvinculación de la escuela: perspectiva del alumnado. Magis, Revista Internacional de Investigación en Educación, v. 6, n. 13, p. 129-142, 2014.

SEDDON, Terri. Making educational spaces through boundary work: territorialisation and 'boundarying'. Globalisation, Societies and Education, v. 12, n. 1, p. 10-31, 2014. doi:10.1080/14767724.2013.858396

SMYTH, John; SHACKLOCK, Geoffrey. Behind the 'Cleansing' of Socially Critical Research Accounts. In: SHACKLOCK, Geoffrey; SMYTH, John (ed.). Being reflexive in critical educational and social research. London: The Falmer, 1998. p. 1-12.

SOUSA SANTOS, Boaventura. A crítica da governação neoliberal: o Fórum Social Mundial como política e legalidade cosmopolita subalterna. Revista Crítica de Ciências Sociais, Coimbra, v. 72, p. 7-44, out. 2005.

TITSCHER, Stefan; MEYER, Michael; WODAK, Ruth; VETTER, Eva. Methods of text and discourse analysis. London: Sage, 2000.

TRIPODI, Zara; SOUSA, Sandra. Do governo à governança: permeabilidade do estado a lógicas privatizantes na educação. Cadernos de Pesquisa, São Paulo, v. 48, n. 167, p. 228-253, jan./mar. 2018.

TYACK, David; TOBIN, William. The "grammar" of schooling: why has it been so hard to change? American Educational Research Journal, v. 31, n. 3, p. 453-479, 1994.

WILLIS, Paul. Learning to labour: how working class kids get working class jobs. Farnborough: Saxon House, 1977.

YOUNG, Michael; MULLER, Johan. Three educational scenarios for the future: lessons from the sociology of knowledge. European Journal of Education, v. 45, n. 1, p. 11-27, 2010.

NOTA: Cada uma das autoras desenvolve, há mais de uma década, pesquisas e análises de políticas públicas e educativas bem como estudos sobre diversidades, desigualdades e participação em educação; este artigo resulta de pesquisa conjunta no âmbito de diversos projetos.

\section{COMO CITAR ESTE ARTIGO}

ANTUNES, Fátima; BARROS, Rosanna. Dimensões biográficas, respostas comunitárias: tensões numa política socioeducacional em Portugal. Cadernos de Pesquisa, São Paulo, v. 49, n. 173, p. 244-265, jul./set. 2019. https://doi.org/10.1590/198053145894 